\title{
A Comparative Study of South Gujarat Urban and Rural Secondary Schools Students' Mental Health
}

\author{
Dr. Milan P. Patel ${ }^{1}$, Dr. Ankur D. Chaudhari ${ }^{2}$ \\ Physical Instructor \\ ${ }^{1}$ College of Veterinary Science and A.H., ${ }^{2}$ N.M. College of Agriculture, \\ Navsari Agricultural University, Navsari, Gujarat, India
}

\begin{abstract}
Mental health of the learner is very important for efficient learning and proper development of personality. For adolescents, school is the most important setting outside the family. Students perceptions of the school environment are significantly associated with their wellbeing. Welldeveloped adolescents who were empowered with appropriate life skills have better chances of becoming healthy, responsible, and productive adults. Students are also having many mental health problems, example, exam phobia, and adjustment problem with teacher, school-family.
\end{abstract}

The purpose of the study was to compare the Mental Health status among South Gujarat Urban and Rural Secondary School Students. Subjects selected for the present study were secondary school students of south Gujarat urban and rural area. A total of 2160 boys student were randomly selected below the age of 15 years. From the city schools 1077 boys and from rural schools 1083 boys were randomly selected. The Mental Health Scale prepared by Dr. D.J. Bhatt and Ms. Geeta R. Geeda was used as a tool for the present study.

The scores arrived from 1077 Urban School students and 1083 Rural School students were compared by applying ' $t$ ' test. This study revealed significant difference in Mental Health Mean Scores between Urban and Rural area Secondary School Students of South Gujarat. This shows that the brought up of the student affects their mental health. The economic development may be one of the factor for the differences in mental health of urban and rural students.

Schools have to play a vital role in improving mental health of students. A mentally healthy student can think positively and cherishes it in any situation. Also mentally healthy student can contribute in developing the society and nation.

Keywords: Mental Health, Urban, Rural, Secondary, School, Students.

\section{INTRODUCTION:}

Mental health is being fit psychological, or an absence of mental illness. It is the psychological state of a person who is at a satisfactory level of emotional and behavioral adjustment. According to the World Health Organization (WHO), mental health includes "subjective well-being, perceived self-efficacy, autonomy, competence, inter-generational dependence, and self actualization of one's intellectual and emotional potential, among others." The WHO further states that the well-being of an individual is encompassed in the realization of their abilities, coping with normal stresses of life, productive work and contribution to their community. Cultural differences, subjective assessments, and competing professional theories all affect how "mental health" is defined. Mental health is a normal state of well-being, a positive way and a quality of life. It is a condition which is characterized of the average person who meets the demands of life on the basis of his own capacities and limitations. It is rooted in his ability to balance feelings, desires, ambitions, ideas and competence.

Today, an individual is facing lots of problems in the human societies. So, it is a challenge for humans to be mentally healthy. Mental health has become very 
importance issue of human life. Mental health of the learner is very important for efficient learning and proper development of personality. For adolescents, school is the most important setting outside the family. Students perceptions of the school environment are significantly associated with their wellbeing. Well-developed adolescents who were empowered with appropriate life skills have better chances of becoming healthy, responsible, and productive adults. Students are also having many mental health problems, example, exam phobia, and adjustment problem with teacher, school- family.

The world is becoming more and more competitive and quality of performance is the key factor for personal progress. Excellence particularly, in academics and generally in all other areas is being the important aspect. All parents desire that their child should be the top performer. This desire of a high level of achievement puts a lot of pressure on students, teachers, institutions and the educational system itself in general. In fact it appears as if the whole system of education revolves around academic achievement of the students, though various other outcomes are also expected from the system.

\section{WHAT RESEARCH SAYS?}

Desai Parulben Harish (2017) studied the mental health of adolescent students of higher secondary school. The study was based on the investigation conducted to study the effect of gender, area of residency and type of family on mental health of adolescent students of higher secondary school of Valsad district in Gujarat state. The sample consisted of 240 higher secondary school students. The sample was selected in terms of sex (male and female), area of residency (rural and urban) and type of family (joint family and nuclear family) in equal proportions, drawn randomly. Mental Health was measured by A K Singh and Alpana Sengupta Test of Mental Health Battery. In this research, ' $t$ ' test method was used for testing of null hypothesis. In the findings of this research, there was a significant difference in mental health between male and female students. Also, there was significant difference between in mental health of rural and urban students. In the last results, there are significant differences in mental health between joint family and nuclear family students. In the conclusions of these researches, male students have good mental health as compared to the female students, rural students have good mental health as compared to the urban students and the joint family students have good mental health as compared to the urban nuclear family students.

Kharod Nikhil \& Kumar Dinesh (2015) studied the mental health status of school going adolescents as part of introducing life skills education. Cross sectional study was carried out among adolescent students (10-19 years) in rural schools of Anand district of Gujarat, using a pre-tested and validated self reported 'Strengths \& Difficulties' Questionnaire (SDQ) in Gujarati language. $605(62.6 \%)$ boys and $361(37.4 \%)$ girls participated in the study. The mean age was 14.2 years (Standard deviation: 1.46). Majority of students $820(84.9 \%)$ attended day schools (9am-5pm). 171 (17\%) students attended tuitions also. Only about $37 \%$ had normal self reported SDQ scores. 30\% had borderline and 33\% had abnormal scores. Highest level of abnormal score was seen in peer problem score $(45.9 \%)$ and least in pro-social behavior score $(1.1 \%)$. The abnormal SDQ score were statistically more among girls, Muslim students, students in primary school, those with problematic families and those attending morning schools. The SDQ can be easily administrated in rural Indian setting by trained non professional personnel including teachers. The high prevalence of abnormal SDQ scores calls for integrating mental health issues and Life skill education in the existing school health programs.

\section{PURPOSE OF THE STUDY}

The purpose of the study was to compare the Mental Health status among South Gujarat Urban and Rural Secondary School Students.

\section{HYPOTHESIS}

It was hypothesized that there will be no significant difference in Mental Health among South Gujarat Urban and Rural Secondary School Students.

\section{METHODOLOGY}

SAMPLE: For the purpose of the study subjects selected for the present study were secondary school students of south Gujarat urban and rural area. A total of 2160 boys student were randomly selected below the age of 15 years. From the city schools 1077 boys and from rural schools 1083 boys were randomly selected.

TOOL: The Mental Health Scale prepared by Dr. D.J. Bhatt and Ms. Geeta R. Geeda was used as a tool for the present study. This scale contains 40 
statements pertaining to five domains, aim of mental health, these five dimensions include perception of reality, integration of personality, positive selfevaluation, group oriented attitudes and environmental mastery to be rated on 3-pointscale.

\section{ANALYSIS}

The scores arrived from 1077 Urban School students and 1083 Rural School students were compared by applying ' $t$ ' test. The resultant value is shown in the table below:

\section{Table - 1 Significant Difference of Mental Health} Among Secondary School Students of South

\begin{tabular}{|c|c|c|c|c|c|}
\multicolumn{7}{|c|}{ Gujarat Urban and Rural Area } \\
\hline Group & $\mathbf{N}$ & Mean & $\begin{array}{c}\text { Std. } \\
\text { Dev. }\end{array}$ & $\begin{array}{c}\text { Mean } \\
\text { Difference }\end{array}$ & $\begin{array}{c}\text { 't' } \\
\text { Ratio }\end{array}$ \\
\hline Urban & 1077 & 25.25 & 5.26 & 2.0189 & $9.181^{*}$ \\
\hline Rural & 1083 & 23.23 & 4.96 & level & \\
\hline \multicolumn{7}{|c|}{ Significant at .05 level } \\
\hline
\end{tabular}

It is evident from the table 1 that there was a significant difference between the mean scores on Mental Health of male students of secondary school from South Gujarat urban and rural area, since the obtained ' $t$ ' value (9.181) is greater than the tabulated value of ' $t$ ' (1.645) which is required to be significant at .05 level. The graphical presentation is as below:

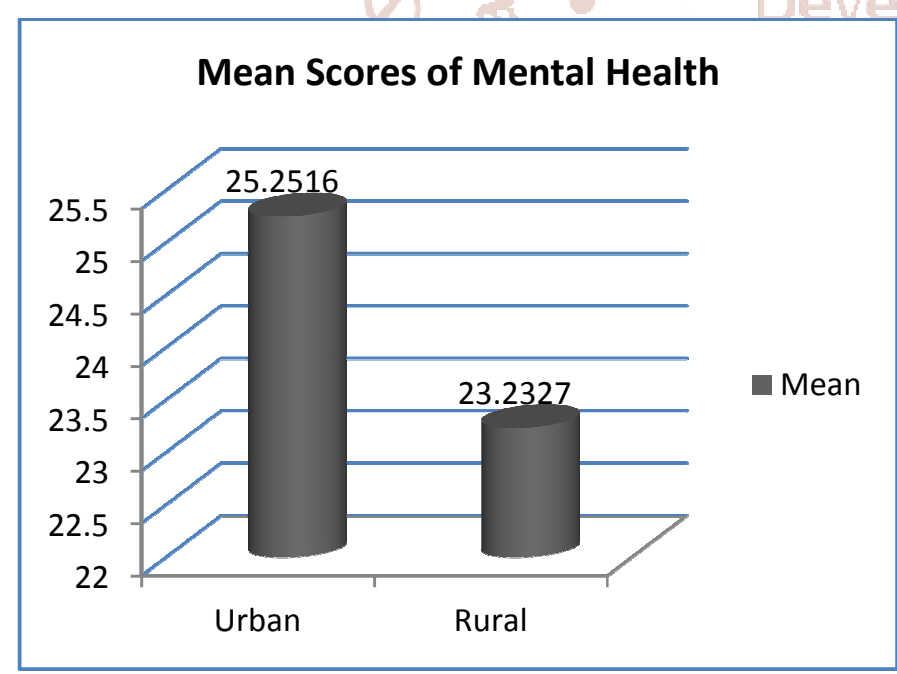

\section{Graph 1: Graphical Representation of Mean Scores of Mental Health among Secondary School Students of South Gujarat Urban and Rural area}

\section{CONCLUSION}

Mental health of the student is very important; the students should feel secure and comfortable in the school. Type of the school has significant influence on the mental health of the student. The student should feel homely atmosphere in the school. At the time of colleting the data from both urban and rural area the researcher had interacted with the teachers and students. It was noticed that the majority of the rural student's parents are illiterates, and they seemed to be first generation learners. The poor conditions of the family, health problems, problems in understanding the subjects, lack of support from the siblings and parents leads to poor mental health of the students. Whereas, the scenario at urban school was totally different, the students are not happy with daily academic activities and rigid time table followed at the school. The teachers are more interested in imposing the syllabus load and insisting the students to score top marks and grades. Unhealthy type of academic competition is being created among the students.

On the basis of the findings of the present study the following conclusion was drawn:

This study revealed significant difference in Mental Health Mean Scores between Urban and Rural area Secondary School Students of South Gujarat. This shows that the brought up of the student affects their mental health. The economic development may be one of the factor for the differences in mental health of urban and rural students.

Schools have to play a vital role in improving mental health of students. A mentally healthy student can think positively and cherishes it in any situation. Also mentally healthy student can contribute in developing the society and nation.

\section{REFERENCES}

1. Bernard, H. (1951). Towards Better Personality Adjustment. New York: MC Graw Hill Book Company.

2. Chaplin, J. (1970). Dictionary of Psychology. New Delhi: Vikas Publishing House.

3. Chaudhary, N. (2001). The Effect of Gender Differences on Occupational Stress \& Mental Health of B.Ed. Students Teachers. Prospective in Psychological Researches, 17-19.

4. Desai, P. H. (2017). A Comparative Study of Mental Health among Rural \& Urban Adolescent Students of Higher Secondary School. 17th World Summit on Positive Psychology, Psychotherapy \& Cognitive Behavioral Science. Toronto, Canada: conferenceseries.com. 
International Journal of Trend in Scientific Research and Development (IJTSRD) ISSN: 2456-6470

5. Gupta, A. (1990). Impact of Techers Influence upon Positive Mental Health of the Pupils. Indian Journal of Psychology, 61-70.

6. Kumar, D. K. (2015). Mental Health Status of School Going Adolescents in Rural Areas of Gujarat. Research Gate .
7. Srinivasulu, B. (2018). A Study on Mental Health Status of the Secondary School Students in SPSR Nellore District. International Research Journal of Multidisiplinary Studies, Vol. 4, No. 2.

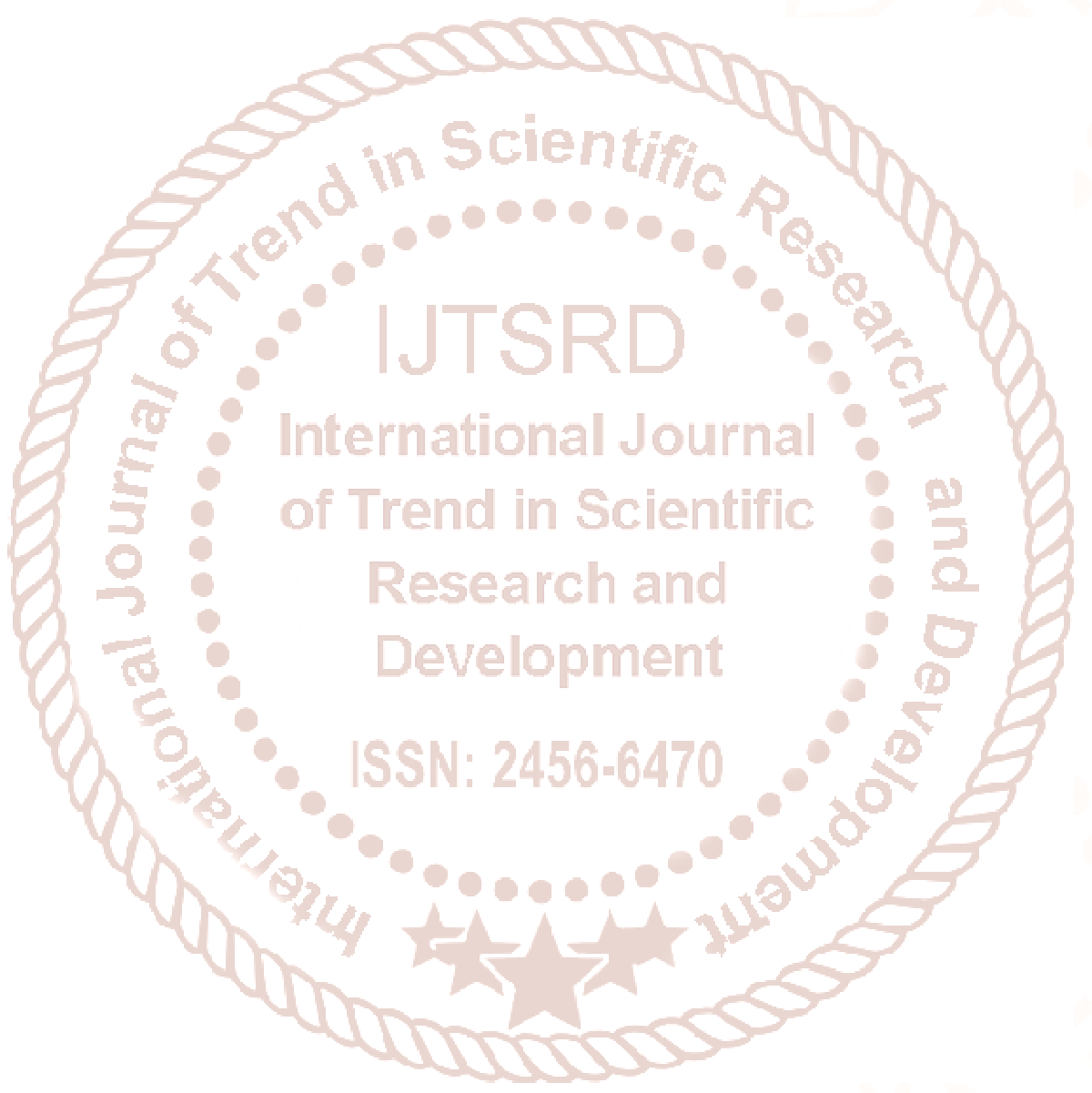

